\title{
Research Paper: Physical Therapy and Rehabilitation Ideas for Inspiratory Muscle Training in Patients With Subacute Stroke
}

\author{
Irma Ruslina Defi ${ }^{*}$ (D), Novitri Novitri' ${ }^{1}$ (D), Ilin Nurina ${ }^{1}$ (C)
}

1. Department of physical Medicine and Rehabilitation, Faculty of Medicine, Padjdjaran University, Sumedang, Indonesia.

\begin{tabular}{|l|l|}
\hline $\begin{array}{c}\text { Use your device to scan } \\
\text { and read the article online }\end{array}$ & $\begin{array}{l}\text { Cittation Defi I, Novitri N, Nurina I. Physical Therapy and Rehabilitation Ideas for Inspiratory Muscle Training in Patients } \\
\text { With Subacute Stroke. Iranian Rehabilitation Journal. 2021; 19(4):455-464. http://dx.doi.org/10.32598/irj.19.4.1290.1 }\end{array}$ \\
\hline
\end{tabular}

Article info:

Received: 01 Dec 2020

Accepted: 19 Nov 2021

Available Online: 01 Dec 2021

Keywords:

Inspiratory muscle training, Lung function, Stroke

\section{ABSTRACT}

Objectives: This study aimed to elucidate the outcome of an Inspiratory Muscle Training (IMT) rehabilitation intervention on the lung function, functional mobilization, balance, and peripheral muscle strength of the paretic side in patients with subacute stroke.

Methods: This double-blind, randomized controlled trial study was conducted on patients with stable subacute stroke. For 8 weeks, the intervention group $(n=16)$ received $40 \%$ intensity IMT while the control group $(\mathrm{n}=16)$ received $10 \%$ intensity IMT. We assessed the patients' lung function (spirometer) before and after the intervention, as well as their pulmonary muscle strength (micro-respiratory pressure meter [RPM]), quadriceps strength (handheld dynamometer), grip strength (Jamar), walking speed (10-m walk test), balance (Berg Balance Scale [BBS]), and functional mobilization (sit-to-stand test).

Results: There were significant differences between the intervention group and the control group after IMT for forced vital capacity $(\mathrm{FVC}) \%(\mathrm{P}<0.01 ; \mathrm{d}=3.20)$, forced expiratory volume in the first second (FEV1)/FVC $(\mathrm{P}<0.001 ; \mathrm{d}=2.55)$, FEV1\% $(\mathrm{P}<0.001 ; \mathrm{d}=5.10)$, walking speed $(\mathrm{P}<0.05 ; \mathrm{d}=1.62)$, hand grip $(\mathrm{P}<0.001 ; \mathrm{d}=2.45)$, quadriceps strength $(\mathrm{P}<0.001 ; \mathrm{d}=4.18)$, functional mobilization $(\mathrm{P}<0.01 ; \mathrm{d}=2.41)$, and maximal inspiratory mouth pressure $(\mathrm{P}<0.001$; $\mathrm{d}=1.62)$, but no significant changes were seen in balance $(\mathrm{P}=0.304 ; \mathrm{d}=0.57)$.

Discussion: IMT improved lung function, functional mobilization, handgrip strength, and quadriceps strength on the paretic side of subacute stroke patients and is expected to improve functional status and allow the patient to participate in social activities. IMT exercise can be included in the rehabilitation program for subacute stroke patients. 


\section{Highlights}

- Inspiratory muscle metaboreflex plays a role in reducing exercise tolerance.

- There was a significant increase in lung function, functional mobilization, grip, and quadriceps paretic side strength after inspiratory muscle training in patients with subacute stroke.

- Exercise should be included in the rehabilitation program of patients with subacute stroke.

\section{Plain Language Summary}

The current study found that an inspiratory muscle training rehabilitation intervention improved lung function, functional mobilization, balance, quadriceps strength, and handgrip strength on the paretic side of subacute stroke patients. Furthermore, based on the findings of this study, we conclude that exercise should be considered part of the rehabilitation program of subacute stroke patients.

\section{Introduction}

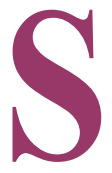

troke is the second cause of death and the third leading cause of disability globally [1]. In 2018, the prevalence of stroke in Indonesia was approximately 10.9 per 1000 population, increasing from 2013 when the prevalence was 7 per 1000 population [2]. About $50 \%-70 \%$ of stroke patients achieve their functional recovery, and $15 \%-30 \%$ have a disability three months after onset [3]. In Asia, there was a large variety of stroke disability-adjusted life-years (DALYs) lost based on age and gender. The DALYs lost show the impact of mortality, incidence, and disability among common cases, and the latter potentially consider the impact of stroke severity and rehabilitative interventions [4].

Peripheral muscles, including those involved in stroke and respiratory muscle weakness, low thorax expansion, and body posture dysfunction, play an essential role in exercise capacity and ability to perform daily tasks $[5,6]$. Hemiparesis in stroke changes the muscle fiber type. Type II fiber composition is increasing to aggravate the patient's mobilization activity, and this type is easily fatigued compared to type I fiber [7].

Smith was the first researcher who found a hemiplegic effect on the diaphragm. He found an elevation difference on the diaphragm in the paretic side compared with the non-paretic side in stroke [8]. Another study on Inspiratory Muscle Training (IMT) discovered that improving inspiratory muscle function increases exercise capacity and balance in chronic stroke patients [9]. Britto et al. administered the IMT program to chronic stroke patients at home based on the intensity of $30 \%$ of Maximal Inspiratory Pressure
(MIP) for eight weeks. They observed a significant increase in respiratory muscle strength and endurance. Therefore, inspiratory muscle training was included as supporting training in stroke patients. This study showed increasing grip strength and quadriceps strength in both paretic and nonparetic sides [10].

Bosnak et al. administered a program with an intensity of MIP $40 \%$ for 30 minutes, seven days per week for six weeks. This program was performed on 30 patients with heart failure (New York Heart Association [NYHA] IIIII, Left Ventricular Ejection Fraction (LVEF) $<40 \%$ ). Sixteen patients underwent IMT at MIP40\%, and 14 patients who underwent placebo therapy (MIP15\%) showed significantly increasing quadriceps femoris strength [11]. Inspiratory muscle fatigue and metabolic accumulation in respiratory muscles activate unmyelinated type IV phrenic afferent fibers, which increase sympathetic reflex outflow and trigger vasoconstrictor response in resting limbs. That condition can improve the patient's heart rate and mean arterial pressure. Moreover, respiratory muscle fatigue, defined as "inspiratory muscle metaboreflex", will limit the perfusion of the limb by activating the sympathetic vasoconstriction reflex, thus reducing exercise tolerance.

The previous study has shown that an oxygen demanddelivery mismatch in respiratory muscles can trigger inspiratory muscle metaboreflex [12]. Inspiratory muscle training can cause systemic training effects such as vasoconstriction on peripheral muscles. Decreasing arterial flow will stimulate baroreceptors to vasodilate peripheral vessels. Continuous training causes vascular adaptation, which results in constant vasodilation, increasing blood flow to the peripheral area, and changing the com- 
position of type I and type II muscle fibers with higher mitochondrial capacity, thus improving the factor for increasing peripheral muscle strength [13].

The objective of this research was to elucidate the effect of an IMT-based rehabilitation intervention on lung function, mobility, balance, quadriceps strength, and handgrip strength on the paretic side of subacute stroke patients.

\section{Methods}

\section{Subjects and design}

We conducted a double-blind, randomized controlled trial. We used the comparative studies formula for sample size calculation. Thirty-five subjects were divided into two groups with a computer-generated block randomized list. The first group is the intervention group, with 17 subjects conducting the IMT at 40\% intensity. The second group is the control group, with 18 subjects performing the IMT at $10 \%$ intensity. Our study was conducted in Hasan Sadikin Hospital from October 2017 until October 2018.

The Profession and Research Ethics Committee of the Medical Committee Faculty of Medicine, Padjadjaran University, provided ethical clearance before the study (ethical clearance number: LB.04.01/A05/EC/220/ VII/2017). As required, the current research's procedures and ethical aspects were carried out in complete accordance with the Declaration of Helsinki. All participants provided written consent for their participation in the recent study.

The inclusion criteria were patients over 34 years, with the first stroke at least two weeks to three months after the stroke. Hemiparesis after stroke is defined by the presence of limb weakness with measurement from manual motor testing, but the subject can still walk with or without tools. The subject should be able to perform a handgrip test, IMT exercise, have a MIP value lower than $70 \%$ of predictive value by age and gender, understand oral and writing instruction (with mini-mental state examination [MMSE] score=22-30), and be cooperative. The exclusion criteria include hearing loss that interferes with understanding verbal instruction, a history of pulmonary obstruction based on spirometry results, previous chest or abdominal surgery, unstable cardiovascular disease, musculoskeletal disorders, and respiratory and expiratory breathing exercises over the last six months. Also, if the subject had contraindications to perform respiratory muscle exercises such as pneumothorax and unstable asthma with abnormally low dyspnea perception, he or she would be excluded from the study. At baseline, we assessed MIP to determine the intensity of IMT. MIP was measured by blowing into a flanged mouthpiece with nose clips in place. The subjects were told to exhale to residual volume. A valve or shutter is closed at residual volume, and the patient is instructed to inhale as forcefully as possible. The maximum pull should be held for 1-2 s [14]. Also, we conducted pulmonary function, peripheral muscle strength (handgrip and quadriceps strength), balance, and walking speed as other outcome measures.

Spirometry was used to assess pulmonary function, including forced expiratory volume in the first second (FEV1) and forced vital capacity (FVC) based on age and gender. Lung function was evaluated by inhaling deeply, holding the breath for a few seconds, and then exhaling as hard as the subject could into the breathing mask. The subjects will repeat this test at least three times to ensure consistent results [15].

Grip strength test assessed using handheld dynamometer with the subject sitting on a chair with $90^{\circ}$ elbow flexion position. The subject is asked to hold the handgrip dynamometer and to grip as much as possible three times. The value taken is the mean of 3 times the test. For quadriceps muscle strength measurement, we used a handheld dynamometer (hydraulic type) with the patient's position sitting on a chair, knee flexed $90^{\circ}$. The measurement was taken three times, and the mean value was recorded.

We used the Berg balance scale (BBS) for the balance test. The BBS is made up of 14 items that are graded on a scale of 0 to 4 . If the participant cannot complete the task, $\mathrm{s} /$ he is assigned 0 , and if the participant can complete the task, s/he is given 4 . The BBS test has a maximum total score of 56 [16].

For functional mobilization measurement, we conducted a sit-to-stand test procedure [17], where subjects sat on a chair without a handrail. The stopwatch was switched on, set for 30 seconds, and then the subjects were asked to stand up from a sitting position. For walking speed measurement, we used the 10-m walk test (MWT).

\section{Protocol for IMT}

The training tools component was explained to subjects. They checked out training tools and sat in a reclining chair with an upright torso position. The pulse oximeter tool was fixed to the subject's finger to monitor the general state of the subjects during the exercise. Then 
the mouthpiece of the IMT exercise without intensity was tucked between the lips and the subjects trying to draw breath from the tool as much as three times breaths. The researcher then determined the intensity of the IMT training tool. The nose clip was attached to the subject's nose to close the nostrils. The subjects then breathed from the mouth while observing general circumstances such as signs of hypoxia. The subjects were asked to breathe with the tool for five sets of 10 to 15 respiratory repetitions per minute, each set interspersed with a 1-min break. The approximate duration of 5 sets of exercises was estimated at 15 minutes for one exercise. A similar procedure was repeated for two consecutive days, resulting in 3 days of familiarization with the tools. The subjects were also asked to continue exercises by repeating the IMT practice procedure at home. The subjects were advised to stop the exercise immediately and seek medical evaluation if they experienced dyspnea or sharp pain on inspiration [14].

The subjects were instructed to fill the diary after each IMT exercise on the available tables at home. Every day, the subjects were monitored via communication media for training support.

Every week the researcher conducted an evaluation based on diary records and subject exercise techniques. If subjects had problems visiting the rehabilitation polyclinic, the researcher would visit them at their houses to conduct the evaluation. Both groups also received a conventional stroke rehabilitation program, besides the IMT training program. After eight weeks, the whole outcome measures were examined again.

\section{Statistical analysis}

The Shapiro-Wilk test was used to determine the normality of the variables. The measurements taken before and after the IMT exercise were compared using an independent samples t-test at a significance level of $\mathrm{P}=0.05$ and analyzed using SPSS IBM, v. 21. The effect size measurement uses a standardized mean difference, which is transformed into a value of $\mathrm{F}$ and can be compared to obtain standardized effect size.

\section{Results}

In the beginning, 35 subjects were included in this study. Then, two subjects in the control group dropped out for unknown reasons, and one subject in the intervention group was excluded due to non-compliance during the exercise program. In the end, we had 32 subjects (Figure 1).
A total of 32 subjects with a Mean \pm SD age of $51.37 \pm 6.009$ years in the $40 \%$ intensity group $(n=16)$ and $53.50 \pm 3.864$ years in the $10 \%$ intensity group $(n=16)$ were analyzed (Table 1). Regarding the baseline, we did not find any difference between groups.

The paired t-test statistical analysis test shows significant differences before and after the intervention in lung function, hand muscle strength, walking speed, balance, inspiration muscle strength, sit-to-stand performance, and quadriceps muscle strength in subacute stroke patients in the $40 \%$ intensity group $(\mathrm{P}<0.05)$.

Using the unpaired t-test analysis, we discovered that changes in $\mathrm{FVC} \%$ were significantly different between groups $(\mathrm{P}<0.01)$ and associated with a significantly higher increase in FEV1\% and FEV1/FVC in groups with IMT40\% intensity compared to groups with IMT10\% intensity $(\mathrm{P}<0.001)$. There was significant improvement within the IMT40\% group in $\mathrm{FVC} \%(74.82 \pm 7.92$ to $76.81 \pm 7.47 ; \mathrm{P}<0.01)$, whereas in the control group, there was no significant improvement in $\mathrm{FVC} \%(66.95 \pm 11.66$ to $66.95 \pm 11.66 ; \mathrm{P}>0.05)$. Note that a Cohen's $\mathrm{d}>0.20$ is considered a small, $>0.50$ a medium, and $>0.80$ a large effect; as these are reference points. The effect size is large in all lung function measurements $(d>0.8)$, which suggests a sustained large effect of lung function improvement with the $40 \%$ intensity of IMT (Table 2 ).

Regarding inspiratory muscle strength measure using MIP, it was significantly improved in $40 \%$ intensity IMT ( $53.92 \pm 9.23$ to $57.28 \pm 9.28 ; \mathrm{P}<0.001)$, but no significant improvement was seen in the control group $(35.27 \pm 15.49$ to $35.91 \pm 15.60 ; \mathrm{P}>0.05)$. There were significant differences between groups in inspiratory muscle strength $(\mathrm{P}<0.001)$, and the effect size results indicate that the intervention group improved $(\mathrm{d}>0.8)$ (Table 2$)$.

The walking speed during 10 MWT in this study significantly improved in the control group $(0.80 \pm 0.081$ to $0.90 \pm 0.163 ; \mathrm{P}=0.038)$, but the improvement was higher in intervention group $(0.98 \pm 0.15$ to $1.25 \pm 0.20 ; \mathrm{P}=0.01)$ with the large effect size $(\mathrm{d}>0.8)$. We discovered significant differences between groups using the unpaired t-test $(\mathrm{P}<0.05)$ (Table 2).

The sit-to-stand test was used in this study to measure functional mobilization. In the intervention group, functional mobilization $(8.71 \pm 1.70$ to $11.28 \pm 1.11 ; \mathrm{P}<0.001)$ significantly increased, as well as in the control group (6.00 \pm 2.16 to $6.71 \pm 1.89 ; \mathrm{P}<0.01)$. The Cohen's $\mathrm{d}$ in Table 2 showed a large effect size $(\mathrm{d}>0.8)$, suggesting a significant improvement in functional mobilization 


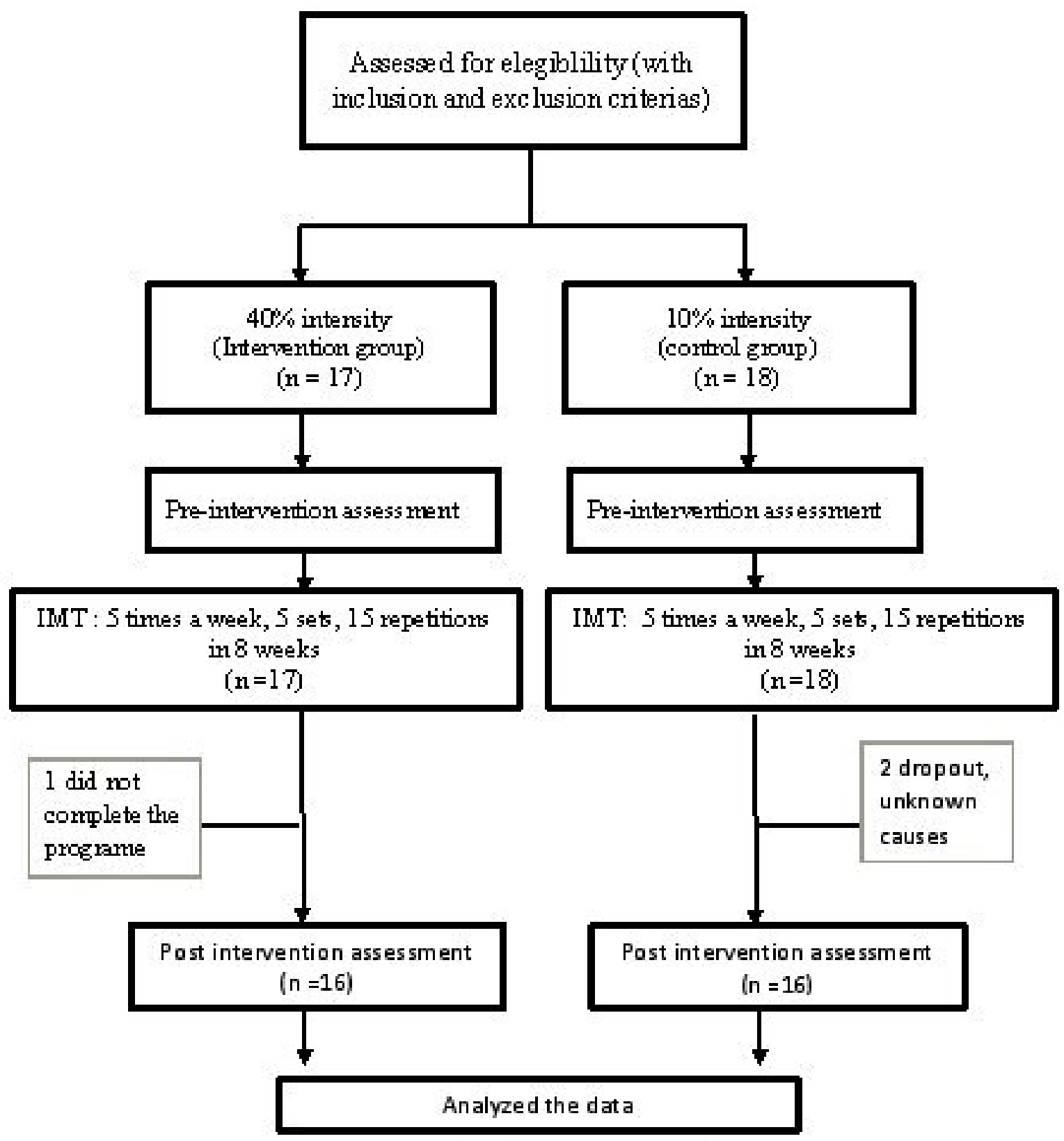

Figure l. CONSORT diagram of study flow chart

Figure 1. CONSORT diagram of study flow chart

Iranian Rehabilitation Journal

in the intervention group. The quadriceps strength and handgrip improved more significantly in the intervention group than in the control group $(\mathrm{P}<0.001)$. The Cohen's $\mathrm{d}$ more than 0.8 in both quadriceps strength $(\mathrm{d}=4.177)$ and handgrip $(\mathrm{d}=2.456)$ on the paretic side indicated a significant effect of the intervention (Table 2).

Using the paired t-test, no significant improvement was found for BBS in the control group (51.85 \pm 4.30 to 52.71 \pm 4.070 ). Although BBS improved significantly within the intervention group (53.14 2.97 to $54.71 \pm 3.50$;
$\mathrm{P}<0.05$ ), there were no significant differences between groups $(\mathrm{P}>0.05)$. However, there was a medium effect size in the intervention group on the BBS value $(\mathrm{d}>0.5)$ (Table 2). We did not find any adverse effects during the IMT program in this study.

\section{Discussion}

Smith et al. and Korczyn et al. reported that hemiplegia in limbs could also occur in the diaphragm [8, 18]. Diaphragm muscle plays a key role in maintaining respiratory 
Table 1. Baseline characteristics (each group: $n=16$ )

\begin{tabular}{|c|c|c|c|}
\hline \multirow[b]{2}{*}{ Variables } & \multicolumn{2}{|c|}{ Mean \pm SD } & \multirow[b]{2}{*}{$\mathbf{P}$} \\
\hline & $\begin{array}{l}\text { Intervention Group } \\
\text { (40\% Intensity) }\end{array}$ & $\begin{array}{l}\text { Control Group } \\
\text { (10\% Intensity) }\end{array}$ & \\
\hline Age (y) & $51.37 \pm 6.009$ & $53.50 \pm 3.864$ & 0.361 \\
\hline Female/male ratio & $7 / 7$ & $7 / 7$ & 1.000 \\
\hline Height (cm) & $158.62 \pm 8.693$ & $154.68 \pm 7.691$ & 0.185 \\
\hline Weight (kg) & $59.80 \pm 10.201$ & $54.43 \pm 11.395$ & 0.171 \\
\hline Stroke onset (month) & $3.06 \pm 0.997$ & $3.37 \pm 0.718$ & 0.468 \\
\hline MMSE & $29.00 \pm 1.095$ & $28.81 \pm 1.682$ & 0.724 \\
\hline $\begin{array}{l}\text { Side paretic ratio } \\
\text { (right/left) }\end{array}$ & $3 / 4$ & $2 / 5$ & 0.280 \\
\hline Infarct/Bleeding ratio & $2 / 5$ & $2 / 5$ & 1.000 \\
\hline
\end{tabular}

system ventilation function. Its weakness will affect the function of lung physiology characterized by decreasing FVC, FEV1, and Peak Expiratory Flow (PEF) up to 50\% from prediction value based on inspection results with spirometry [19]. The results of FVC lung function in both groups after IMT exercise showed significant changes.

Our results were in line with Gomez et al. study results showing a significant increase in FVC results in spirometry in stroke patients who received strength training for respiratory muscles compared to the control group [20]. Similar findings by Sutbeyaz et al. showed that stroke patients had a significant increase in FVC after six weeks of respiratory breathing exercises [21]. Respiratory muscle weakness due to stroke can affect the effectiveness of cough characterized in stroke patients, decreasing by $50 \%$ compared to healthy subjects $[22,23]$. Respiratory muscle response to exercise is similar to other skeletal muscle responses. Muscles will adapt to the changes in structure that will improve their function.

Based on previous studies of respiratory muscle exercises in stroke patients, the intensity of $30 \%$ to $60 \% \mathrm{MIP}$ often produces a significant effect. Intensity below $30 \%$ MIP was declared ineffective to increase inspiratory muscle strength; it is often used for placebo/sham effect $[9,10,13]$. Our study used an intensity of $40 \%$ MIP for the intervention group and an intensity of $10 \%$ MIP for the control group.

The function of the upper limbs is closely related to the performance of daily activities. Handgrip strength is a vital recovery factor in stroke patients and affects their daily activities [12]. According to Table 2, the handgrip strength showed statistically significant differences before and after the exercise in both groups.

Sit-to-Stand performance is related to the functional measurement of mobilization, such as walking speed, ambulation independence, and climbing stairs [24]. Sitting and standing are prerequisites of daily activity, and these actions are primarily impaired in stroke patients. The ability to stand up mainly depends on the strength of the quadriceps femoris muscle [25]. Based on sit-tostand measures, we found a statistically significant difference between groups.

Our research found that vasodilation in the peripheral muscles caused by baroreceptor stimulation increased muscle strength and standing performance. Initially, vasoconstriction occurs in peripheral muscles due to metabolite accumulation in the hemiparesis diaphragm [12]. Continuous IMT will result in vascular adaptation and improve endothelial function that will change the type of peripheral muscle cells due to increased oxygenation. Change of muscle type can also increase the strength of peripheral muscles.

Table 2 shows significant differences in quadriceps femoral muscle strength within and between groups. Our result is in line with the research conducted by Bosnak et al. [11]. Yao et al. reported that respiratory muscle exercises could increase the maximum pressure of inspiration, lung function, endurance, and peripheral muscle strength after eight weeks of exercise [3]. 
Table 2. Before and after inspiratory muscle training results

\begin{tabular}{|c|c|c|c|c|c|c|c|}
\hline \multirow{2}{*}{ Variables } & \multirow{2}{*}{$\begin{array}{c}\text { Before/ } \\
\text { After }\end{array}$} & \multicolumn{4}{|c|}{ Mean $\pm S D$} & \multirow{2}{*}{$\begin{array}{c}\text { Intra-group } \\
\mathbf{P}\end{array}$} & \multirow{2}{*}{$\begin{array}{c}\text { Effect size } \\
\text { Cohen's } \\
\text { d (d) }\end{array}$} \\
\hline & & $\begin{array}{l}\text { Intervention } \\
\text { Group } \\
\text { (40\% Intensity) }\end{array}$ & $\mathbf{P}$ & $\begin{array}{c}\text { Control Group } \\
\text { (10\% Intensity) }\end{array}$ & $\mathbf{P}$ & & \\
\hline FVC (\%) & $\begin{array}{l}\text { Before } \\
\text { After }\end{array}$ & $\begin{array}{l}74.82 \pm 7.923 \\
76.81 \pm 7.474\end{array}$ & $0.001^{* *}$ & $\begin{array}{l}63.95 \pm 11.659 \\
66.95 \pm 11.659\end{array}$ & 1.000 & $0.001^{* *}$ & 3.199 \\
\hline FEV1/FVC (\%) & $\begin{array}{l}\text { Before } \\
\text { After }\end{array}$ & $\begin{array}{l}89.81 \pm 5.053 \\
91.72 \pm 5.309\end{array}$ & $0.000 * * *$ & $\begin{array}{l}80.15 \pm 4.665 \\
85.87 \pm 4.772\end{array}$ & $0.011^{*}$ & $0.000 * * *$ & 2.551 \\
\hline FEV1 (\%) & $\begin{array}{l}\text { Before } \\
\text { After }\end{array}$ & $\begin{array}{l}86.65 \pm 10.422 \\
88.45 \pm 10.479\end{array}$ & $0.000 * * *$ & $\begin{array}{l}60.87 \pm 28.759 \\
61.21 \pm 28.831\end{array}$ & $0.003^{* *}$ & $0.000 * * *$ & 5.102 \\
\hline Handgrip (kg) & $\begin{array}{l}\text { Before } \\
\text { After }\end{array}$ & $\begin{array}{l}13.65 \pm 2.784 \\
16.82 \pm 2.864\end{array}$ & $0.002^{* *}$ & $\begin{array}{l}9.35 \pm 2.836 \\
9.82 \pm 2.821\end{array}$ & $0.004 * *$ & $0.000 * * *$ & 2.456 \\
\hline $\begin{array}{l}\text { Sit-to-Stand test } \\
\text { (s) }\end{array}$ & $\begin{array}{l}\text { Before } \\
\text { After }\end{array}$ & $\begin{array}{c}8.71 \pm 2.774 \\
11.28 \pm 1.112\end{array}$ & $0.000^{* * *}$ & $\begin{array}{l}6.00 \pm 2.160 \\
6.71 \pm 1.889\end{array}$ & $0.008^{* *}$ & $0.001^{* *}$ & 2.407 \\
\hline $\begin{array}{l}\text { Quad. } \\
\text { Strength }\end{array}$ & $\begin{array}{l}\text { Before } \\
\text { After }\end{array}$ & $\begin{array}{l}14.70 \pm 1.990 \\
16.74 \pm 1.925\end{array}$ & $0.000 * * *$ & $\begin{array}{l}12.78 \pm 4.366 \\
13.04 \pm 4.434\end{array}$ & $0.012^{*}$ & $0.000^{* * *}$ & 4.177 \\
\hline PI Max & $\begin{array}{l}\text { Before } \\
\text { After }\end{array}$ & $\begin{array}{l}53.92 \pm 9.229 \\
57.28 \pm 9.275\end{array}$ & $0.000^{* * *}$ & $\begin{array}{l}35.27 \pm 15.485 \\
35.91 \pm 15.599\end{array}$ & 0.06 & $0,000^{* * *}$ & 3.781 \\
\hline $\begin{array}{l}\text { Walking Speed } \\
(\mathrm{m} / \mathrm{s})\end{array}$ & $\begin{array}{l}\text { Before } \\
\text { After }\end{array}$ & $\begin{array}{l}0.98 \pm 0.146 \\
1.25 \pm 0.198\end{array}$ & $0.001 * *$ & $\begin{array}{l}0.80 \pm 0.081 \\
0.90 \pm 0.163\end{array}$ & $0.038^{*}$ & $0.011^{*}$ & 1.619 \\
\hline BBS score & $\begin{array}{l}\text { Before } \\
\text { After }\end{array}$ & $\begin{array}{l}53.14 \pm 2.968 \\
54.71 \pm 3.496\end{array}$ & $0.017^{*}$ & $\begin{array}{l}51.85 \pm 4.296 \\
52.71 \pm 4.070\end{array}$ & 0.111 & 0.304 & 0.574 \\
\hline
\end{tabular}

${ }^{*} \mathrm{P}<0.05 ;{ }^{* *} \mathrm{P}<0.01 ;{ }^{* * *} \mathrm{P}<0.001$.

Iranian Rehabilitation Journa

FVC: forced vital capacity; FEV1: forced expiratory volume in 1s; PIMax: maximal inspiratory mouth pressure; Quad: quadriceps. Intra-group analysis used paired t-test, and inter-group used unpaired t-test.

Table 2 shows that BBS results significantly differed after exercise compared with BBS before exercise in the intervention group. These results are in line with the studies of Bosnak et al. [11] and Dongha et al. [9]. Their research showed increasing strength of quadriceps femoris and inspiratory muscles, indicating that breathing exercise will help improve balance in stroke patients. In these two previous studies, the BBS increase might occur due to decreased fatigue in the diaphragm muscle. Reducing fatigue in the diaphragm will increase the proprioceptive sensitivity in the lumbar area, so it will help improve the balance.

Walking is an essential human activity to enable engagement in the community. Fifty percent of post-stroke patients who can walk have decreased walking speed.
Richards et al. stated that the stroke walking speed of the subacute phase is less than $0.5 \mathrm{~m} / \mathrm{s}$. Normal walking for the functional activity will take at least $0.8 \mathrm{~m} / \mathrm{s}$ to allow a person to get involved in the community $[24,25]$.

Walking speed is also influenced by cardiorespiratory fitness [24]. Exercise of respiratory muscle can improve lung and cardiopulmonary functions [7, 20]. The power of inspiratory muscle will change the perception of effort in the respiratory system and peripheral muscle by decreasing feedback of afferent nervous system III and IV from respiratory muscle and limb muscle. Blood flow to peripheral muscles will remain intact, and muscle performance will last longer during activity [20]. 
According to our research, this exercise can be considered in the rehabilitation program of subacute stroke patients. Our study did not check the long-term effects after exercise. Generalization should be used with caution, and further research is recommended with a larger population.

\section{Conclusion}

In our study, an IMT program with a $40 \%$ intensity for eight weeks improved lung function, hand muscle strength, quadriceps muscle ipsilateral strength, sit-tostand performance, balance, and walking speed in subacute stroke patients.

\section{Ethical Considerations}

\section{Compliance with ethical guidelines}

This study was approved by The Profession and Research Ethics Committee of the Medical Committee Faculty of Medicine, Padjadjaran University (LB.04.01/ A05/EC/220/VII/2017).

\section{Funding}

This study was supported by grants from Padjadjaran University (Grant No.: 885/UN6.3.1/PL/2017, 2017).

\section{Authors' contributions}

All authors equally contributed to preparing this article.

Conflict of interest

The authors declared no conflict of interest.

\section{Reference}

[1] Ali A, Ali NS, Tariq MA, Iftikhar W, Alvi ZZ. Advances in stroke management 2018: A literature review. Journal of Neurological Disorders \& Stroke. 2018; 6(2):1141. https:/ / www.semanticscholar.org/paper/818d6e3044388178bafa6a4b

[2] Indonesia, Ministry of Health. Riset Kesehatan Dasar Nasional (National Basic Health SurveY). Jakarta: MOH of Indonesia; 2018.

[3] Yao XY, Lin Y, Geng JL, Sun YM, Chen Y, Shi GW, et al. Ageand gender-specific prevalence of risk factors in patients with first-ever ischemic stroke in china. Stroke Research and Treatment. 2012; 2012:136398. [DOI:10.1155/2012/136398] [PMID] [PMCID]

[4] Venketasubramanian N, Yoon BW, Pandian J, Navarro JC. Stroke epidemiology in South, East, and South-East Asia: A review. Journal of Stroke. 2017; 19(3):286-94. [DOI:10.5853/ jos.2017.00234] [PMID] [PMCID]
[5] Harvey R, Roth E, Yu D, Celnik P. Stroke Syndrome. In: Braddom PR, editor. Physical medicine and rehabilitation. 4th ed Philadelphia: Elsevier Saunders; 2011. [DOI:10.1016/B978-14377-0884-4.10050-3]

[6] Polese JC, Pinheiro MB, Faria CD, Britto RR, Parreira VF, Teixeira-Salmela LF. Strength of the respiratory and lower limb muscles and functional capacity in chronic stroke survivors with different physical activity levels. Brazilian Journal of Physical Therapy. 2013; 17(5):487-93. [DOI:10.1590/S1413-35552012005000114] [PMID]

[7] McConnell A. Respiratory muscle training: Theory and practice Edinburgh: Elsevier/Churchill Livingston; 2013. [DOI:10.1016/ B978-0-7020-5020-6.00006-6]

[8] Smith M. The effect of hemiplegia on the diaphragm. The American Review of Respiratory Disease. 1964; 89:450-2. [DOI:10.1164/ arrd.1964.89.3.450]. [PMID]

[9] Oh D, Kim G, Lee W, Shin MM. Effects of inspiratory muscle training on balance ability and abdominal muscle thickness in chronic stroke patients. Journal of Physical Therapy Science. 2016; 28(1):107-11. [DOI:10.1589/jpts.28.107] [PMID] [PMCID]

[10] Britto RR, Rezende NR, Marinho KC, Torres JL, Parreira VF, Teixeira-Salmela LF. Inspiratory muscular training in chronic stroke survivors: A randomized controlled trial. Archives of Physical Medicine and Rehabilitation. 2011; 92(2):184-90. [DOI:10.1016/j.apmr.2010.09.029] [PMID]

[11] Bosnak-Guclu M, Arikan H, Savci S, Inal-Ince D, Tulumen E, Aytemir K, et al. Effects of inspiratory muscle training in patients with heart failure. Respiratory Medicine. 2011; 105(11):1671-81 [DOI:10.1016/j.rmed.2011.05.001] [PMID]

[12] Moreno AM, Toledo-Arruda AC, Lima JS, Duarte CS, Villacorta H, Nóbrega ACL. Inspiratory muscle training improves intercostal and forearm muscle oxygenation in patients with chronic heart failure: Evidence of the origin of the respiratory metaboreflex. Journal of Cardiac Failure. 2017; 23(9):672-9. [DOI:10.1016/j. cardfail.2017.05.003] [PMID]

[13] Silva SM, Corrêa JC, da Silva FC, Sampaio LM, Corrêa FI. Comparison of respiratory muscle strength between elderly subjects after a stroke. Acta Fisiatrica. 2013; 20(1):20-3. [DOI:10.5935/01047795.20130004

[14] Neder JA, Andreoni S, Lerario MC, Nery LE. Reference values for lung function tests. II. Maximal respiratory pressures and voluntary ventilation. Brazilian Journal of Medical and Biological Research. 1999; 32(6):719-27. [DOI:10.1590/S0100879X1999000600007] [PMID]

[15] Morris JF. Spirometry in the evaluation of pulmonary function. Western Journal of Medicine. 1976; 125(2):110-8. [PMCID]

[16] Berg KO, Wood-Dauphinee SL, Williams JI, Maki B. Measuring balance in the elderly: Validation of an instrument. Canadian Journal of Public Health. 1992; 83(S 2):S7-11. [PMID]

[17] Jones CJ, Rikli RE, Beam WC. A 30-s chair-stand test as a measure of lower body strength in community-residing older adults. Research Quarterly for Exercise and Sport. 1999; 70(2):113-9. [DO I:10.1080/02701367.1999.10608028] [PMID]

[18] Korczyn AD, Hermann G, Don R. Diaphragmatic involvement in hemiplegia and hemiparesis. Journal of Neurology Neurosurgery, and Psychiatry. 1969; 32(6):588-90. [DOI:10.1136/ jnnp.32.6.588] [PMID] [PMCID]

[19] Khedr EM, El Shinawy O, Khedr T, Aziz Ali YA, Awad EM. Assessment of corticodiaphragmatic pathway and pulmonary function in acute ischemic stroke patients. European 
Journal of Neurology. 2000; 7(3):323-30. [DOI:10.1046/j.14681331.2000.00104.x] [PMID]

[20] Gomes-Neto M, Saquetto MB, Silva CM, Carvalho VO, Ribeiro N, Conceição CS. Effects of respiratory muscle training on respiratory function, respiratory muscle strength, and exercise tolerance in patients poststroke: A systematic review with meta-analysis. Archives of Physical Medicine and Rehabilitation. 2016; 97(11):1994-2001. [DOI:10.1016/j. apmr.2016.04.018] [PMID]

[21] Sutbeyaz ST, Koseoglu F, Inan L, Coskun O. Respiratory muscle training improves cardiopulmonary function and exercise tolerance in subjects with subacute stroke: A randomized controlled trial. Clinical Rehabilitation. 2010; 24(3):240-50. [DOI:10.1177/0269215509358932] [PMID]

[22] Messaggi-Sartor M, Guillen-Solà A, Depolo M, Duarte E, Rodríguez DA, Barrera MC, et al. Inspiratory and expiratory muscle training in subacute stroke: A randomized clinical trial. Neurology. 2015; 85(7):564-72. [DOI:10.1212/ WNL.0000000000001827] [PMID]

[23] Ward K, Seymour J, Steier J, Jolley C, Polkey M, Kalra $\mathrm{L}$, et al. Acute ischaemic hemispheric stroke is associated with impairment of reflex in addition to voluntary cough. European Respiratory Journal. 2010; 36(6):1383-90. [DOI:10.1183/09031936.00010510] [PMID]

[24] Richard CL, Sharon WD, Malouin F. Outcomes measurement: Basic principles and applications in stroke rehabilitation. In: Michael E, Clarke S, Cohen L, Duncan P, Gage F, editors. Textbook of neural repair and rehabilitation medical neurorehabilitation. 1th ed. New York: Cambridge University Press; 2006. [DOI:10.1017/CBO9780511545078.003] [PMID]

[25] Boukadida A, Piotte F, Dehail P, Nadeau S. Determinants of sit-to-stand tasks in individuals with hemiparesis post stroke: A review. Annals of Physical and Rehabilitation Medicine. 2015; 58(3):167-72. [DOI:10.1016/j.rehab.2015.04.007] [PMID] 
This Page Intentionally Left Blank 